\title{
Intensified insulin therapy and the risk of severe hypoglycaemia
}

\author{
S. B ott, U . B ott, M . B erger, I. M ühlhauser \\ Department of Metabolic Diseases and Nutrition (WHO-Collaborating Centre for Diabetes), Heinrich-Heine-University, \\ Düsseldorf, Germany
}

Summary The objectives of the present analyses were to assess the association between $\mathrm{HbA}_{1 \mathrm{c}}$ levels and severe hypoglycaemia ( $\mathrm{SH}$, treatment with glucose i.v. or glucagon injection) and to identify predictors of $\mathrm{SH}$ in a prospective multicentre trial. The study population consisted of 636 insulin-dependent diabetic patients who had participated in a structured 5-day in-patient group treatment and teaching programme for intensification of insulin therapy (ITTP) in one of 10 hospitals and who were re-examined after 1, 2, 3, and 6 years including assessment of demographic, disease and treatment related parameters, diabetes-related knowledge, behaviour, and emotional coping. At baseline, age (mean \pm SD) was $27 \pm 7$ years, diabetes duration $9 \pm 7$ years and $\mathrm{HbA}_{1 \mathrm{c}} 8.3 \pm 1.9 \%$. During the 6-year follow-up, the mean $\mathrm{HbA}_{1 \mathrm{c}}$ value improved to $7.6 \%$, and in patients with a diabetes duration of more than 1 year at entry into the study $(n=538)$ the incidence of SH decreased from 0.28 cases/patient/year during the year preceding the ITTP to 0.17 cases/patient/year. The patient group was divided into decile groups according to mean follow-up $\mathrm{HbA}_{1 \mathrm{c}}$ values. In each group more than 230 patient years could be analysed. Groups with mean $\mathrm{HbA}_{1 \mathrm{c}}$ values of 5.7, 7.0, 7.4, 7.7 and $8.9 \%$ had comparable risks of SH (0.15-0.19 cases/ patient/year). In a logistic regression analysis, mean $\mathrm{HbA}_{1 \mathrm{c}}$ during follow-up, a history of $\mathrm{SH}$ during the year preceding the ITTP, C-peptide level, emotional coping, carrying emergency carbohydrates (as assessed at the 1-year follow-up), and age at onset of diabetes were significant independent predictors of $\mathrm{SH}$. The incidence of $\mathrm{SH}$ between centres varied between 0.05 and 0.27 cases/patient/year. In conclusion, in the present analyses no linear or exponential relationship between $\mathrm{HbA}_{1 \mathrm{c}}$ and severe hypoglycaemia could be identified by using simple group comparisons. Applying complex regression analyses, various patient-related predictors of severe hypoglycaemia were identified. [Diabetologia (1997) 40: 926-932]

Keywords Insulin therapy, hypoglycaemia, $\mathrm{HbA}_{1 \mathrm{c}}$, patient education, centre effect.
In the Diabetes Control and Complications Trial (DCCT) intensification of insulin therapy was associated with a threefold increase in the incidence of severe hypoglycaemia when compared to conventional

Received: 23 January 1997 and in revised form: 1 April 1997

Corresponding author: Dr. S. Bott, Heinrich-Heine-Universität Düsseldorf, Klinik für Stoffwechselkrankheiten und Ernährung, Moorenstraße 5, D-40225 Düsseldorf, Germany A bbreviations: DCCT, Diabetes Control and Complications Trial; IDDM, insulin-dependent diabetes mellitus; ITTP, intensified insulin therapy programme. insulin therapy, and there was a strong inverse exponential association between the frequency of severe hypoglycaemia and $\mathrm{HbA}_{1 \mathrm{c}}$ levels [1]. This is in accordance with a recent meta-analysis of randomized controlled studies on intensified insulin therapy [2]. However, among the 29 centres participating in the DCCT there was a substantial variation by clinic in the risk of severe hypoglycaemia associated with intensification of insulin therapy (between 0 and 150 episodes per 100 patient-years) despite a narrow range of variation in the median $\mathrm{HbA}_{1 \mathrm{c}}$ values (between 6.7 and $7.2 \%$ ) [3]. In addition, apart from the DCCT, there are diabetes centres with patients 
predominantly treated by conventional insulin therapy reporting high rates of severe hypoglycaemia and high levels of $\mathrm{HbA}_{1 \mathrm{c}}$ [4-6]. Other diabetes centres have shown that intensification of insulin therapy was not associated with an increased risk of severe hypoglycaemia [7-15]. These differences between centres cannot be simply explained by differences in the achieved degree of metabolic control, the definition and ascertainment of severe hypoglycaemia or patient characteristics [15]. Hence, these studies suggest that intensified insulin therapy is not necessarily associated with a high risk of severe hypoglycaemia, and that conventional insulin therapy does not necessarily protect from an excessively high risk of severe hypoglycaemia. In addition, in the DCCT, among the intensively treated patients less than $10 \%$ of the variation in severe hypoglycaemia (using time intervals as the dependent variable) could be explained by patient characteristics including $\mathrm{HbA}_{1 \mathrm{c}}$ levels [16]. In fact, the DCCT supports the assumption that patient related factors and hypoglycaemia ascertainment cannot explain the centre-effect, since in this trial all of these variables had been standardized. Rather, the centre effect might be due to differences in the performance of intensified insulin therapy, including differences in the strategies of insulin substitution, objectives, contents, intensity and quality of diabetes education, and health beliefs and attitudes of the health care team towards usefulness and safety of intensified insulin therapy. In the DCCT, insulin therapy and patient education were not standardized. Meta-analyses on intensified insulin therapy conceal possibly important differences with respect to treatment and teaching methods and overall diabetes care performance between centres $[2,17]$.

In our recent multicentre study including a large cohort of 636 insulin-dependent diabetic (IDDM) patients intensification of insulin therapy was associated with both a decrease in $\mathrm{HbA}_{1 \mathrm{c}}$ levels and a decrease in the risk of severe hypoglycaemia [10]. At baseline, all patients had participated in the same comprehensive and structured treatment and teaching programme in one of the 10 participating centres. The aim of the present analysis was to describe the association between $\mathrm{HbA}_{1 \mathrm{c}}$ levels and the incidence of severe hypoglycaemia in this group of patients and to identify potential predictors of severe hypoglycaemia during a 6-year follow-up period.

\section{Subjects and methods}

The study population consists of 636 IDDM patients $(81 \%$ of the original cohort of 784 consecutively referred patients) who had taken part in a German multicentre intervention trial which documented the feasibility to translate a treatment and teaching programme for intensification of insulin therapy (ITTP) from a specialized University diabetes centre to general internal medicine hospitals [10], and who were re-examined after 1, 2, 3 and 6 years. Since the outcome was not significantly different for the specialized centre and the nine participating general hospitals, for the purpose of the present study the combined group of 636 patients was analysed. Detailed descriptions of the study population, the ITTP, translation of the ITTP, medical care of the patients after discharge, evaluation protocols, drop outs, and results for up to 6 years have been published [10,18-20]. In short, patients with IDDM were considered eligible for recruitment if they fulfilled the following criteria: age between 15 and 40 years, absence of advanced diabetic late complications (serum creatinine $>177 \mu \mathrm{mol} / \mathrm{l}$; blindness), residence within $100 \mathrm{~km}$ from the respective hospital. A history of repeated or unexplained severe hypoglycaemia was not an exclusion criteria. After discharge patients were primarily followed up by their family physician [10].

The objectives of the 5-day in-patient group ITTP were to enable patients to improve glycaemic control without increasing the risk of severe hypoglycaemia and to liberalize the diet $[10,15,18]$. Patients were advised to measure blood glucose before main meals and at bedtime and to inject NPH insulin in the morning and at bedtime and regular insulin before meals. Day-to-day adaptation of insulin dosages by the patients themselves according to blood glucose values and varying amounts of carbohydrate intake was considered a prerequisite for achieving the treatment goals. The teaching was delivered by a nurse educator and a dietitian in a structured programme which is based on a written curriculum including learning objectives and teaching methods [21].

The follow-up examinations were performed by four trained investigators, who had not been involved in the care of the patients [10,18-20]. Severe hypoglycaemia was defined as a self-reported episode of hypoglycaemia necessitating treatment with intravenous glucose or glucagon injection. Using this definition of severe hypoglycaemia, recording of blood glucose values was not mandatory. Severe hypoglycaemia was assessed at each examination retrospectively for the preceding year [10]. The reference range for $\mathrm{HbA}_{1 \mathrm{c}}$ levels as measured by the Diamat HPLC-method (Biorad, München, Germany) is 4.3-6.1\% [18, 19]. Random C-peptide levels were measured using a human C-peptide assay (Behring, Marburg, Germany). A value of less than $0.1 \mathrm{nmol} / \mathrm{l}$ was considered negative.

As potential predictors of severe hypoglycaemia during the follow-up period the following variables were considered: 1) Baseline demographic data: gender, age, diabetes duration, age at onset of diabetes; 2) Diabetes-related parameters: mean ( = mean of values assessed at $1,2,3$, and 6 years of follow-up) $\mathrm{HbA}_{1 \mathrm{c}}$ during the follow-up period, severe hypoglycaemia during the year preceding the ITTP, insulin dose (IU/kg body weight), percentage of regular insulin of total daily insulin dose, and C-peptide levels at the 1-year follow-up, and centre in which the ITTP was performed. 3) Psychosocial and behaviour-related parameters at the 1-year follow-up: diabetesrelated knowledge using a validated questionnaire with 39 items $[22,23]$, emotional coping using a validated subscale of the ATT39 test [19, 23-25], and compliance to carrying emergency carbohydrates for the treatment of hypoglycaemia.

To identify variables which are able to predict prospectively the long-term risk of severe hypoglycaemia treatment related, behavioural and psychosocial variables at the 1-year followup were considered. The 1-year follow-up was the first occasion to assess changes in insulin treatment, knowledge, compliance and emotional coping after participation in the ITTP.

Statistical analysis. To determine significant predictors of severe hypoglycaemia a stepwise logistic regression analysis was performed. For parameter estimation maximum likelihood methods and for significance testing Wald's chi ${ }^{2}$ statistic were 
used. Parameters were regarded as significant at $p$ less than 0.05 .

Changes over time within the total study population, comparing baseline values and mean values over the 6-year follow-up period were tested for statistical significance by the paired samples t-test and the Wilcoxon signed-ranks test. For comparisons of independent samples t-test, Mann-Whitney Utest and chi-square test were applied. For computations SPSS/ $\mathrm{PC}^{+}$and SAS procedure PROC LOGISTIC was used [26-28].

\section{Results}

At baseline, mean age of the 636 patients ( $48 \%$ women) was $27 \pm 7$ years, diabetes duration $8 \pm 7$ years, body mass index $22.7 \pm 2.9 \mathrm{~kg} / \mathrm{m}^{2}$, and $\mathrm{HbA}_{1 \mathrm{c}}$ $8.3 \pm 1.9 \%$. The mean $\mathrm{HbA}_{1 \mathrm{c}}$ during follow-up was $7.6 \pm 1.3 \%$ ( $p<0.001$ compared to baseline $)$. Among patients with a diabetes duration of more than 1 year at entry into the study $(n=538) 27 \%$ had a history of severe hypoglycaemia and $15 \%$ had experienced at least one severe hypoglycaemic episode during the year preceding the ITTP. The incidence of severe hypoglycaemia of these 538 patients decreased from $0.28 \mathrm{cases} / \mathrm{patient} / \mathrm{year}$ during the year preceding the ITTP to $0.17 \mathrm{cases} / \mathrm{patient} / \mathrm{year}$ during the 6-year follow-up period. Figure 1 shows the course of $\mathrm{HbA}_{1 \mathrm{c}}$ levels and the incidence of severe hypoglycaemia at baseline and at the four follow-up examinations over 6 years. Although $\mathrm{HbA}_{1 \mathrm{c}}$ was improved, particularly over the first 3 years of follow-up, the incidence of severe hypoglycaemia decreased from 0.28 the year preceding the programme to about 0.20 after one $(p<0.05)$, two $(p<0.06)$ and 6 years $(p<0.05)$ and $0.13(p<0.001)$ after 3 years. The percentage of patients who had experienced at least one episode of severe hypoglycaemia was $15 \%$ in the year preceding the ITTP and $11,12,10$ and $12 \%$, respectively after $1,2,3$ and 6 years $[10,20]$.

Table 1 compares patients with at least one severe hypoglycaemic episode during follow-up and those without. Patients with at least one severe hypoglycaemia had lower mean $\mathrm{HbA}_{1 \mathrm{c}}$ levels, a higher daily insulin dose, they had a longer diabetes duration, were younger at onset of diabetes, they had less emotional coping abilities, more of them were C-peptide negative, and they had a more than threefold higher risk of having experienced severe hypoglycaemia during the year preceding the ITTP.

In accordance with the DCCT analysis [1], patients were divided into decile groups of mean $\mathrm{HbA}_{1 \mathrm{c}}$ during the 6-year follow-up (Fig.2). In contrast to the DCCT, the present analysis revealed no exponential association between $\mathrm{HbA}_{1 \mathrm{c}}$ and severe hypoglycaemia. Groups with mean $\mathrm{HbA}_{1 \mathrm{c}}$ values of $5.7 \%$ (range: $4.9-6.1 \%), 7.0 \% \quad(6.9-7.1 \%), 7.4 \%$ (7.1$7.5 \%), 7.7 \%(7.5-7.8 \%)$ and $8.9 \%(8.6-9.3 \%)$ had a comparable risk of severe hypoglycaemia (between 0.15 and 0.19 cases/patient/year).

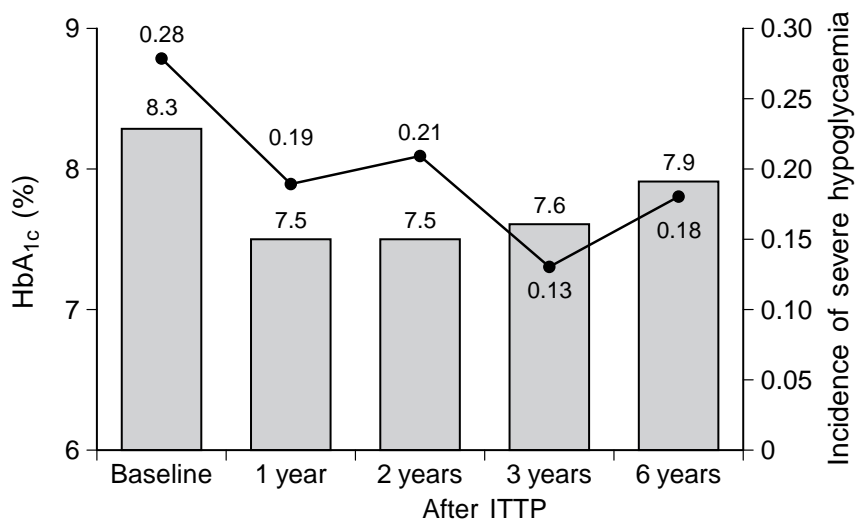

Fig. 1. $\mathrm{HbA}_{1 \mathrm{c}}$ and incidence of severe hypoglycaemia (per patient/preceding year) at baseline and at the follow-up examinations in patients with a diabetes duration $>1$ year at entry into the study $(\mathrm{n}=538)$. ITTP, Intensified treatment and teaching programme

Table 1. Comparison of patients with at least one severe hypoglycaemia during follow-up and patients without severe hypoglycaemia

\begin{tabular}{|c|c|c|}
\hline & $\begin{array}{l}\text { Patients with } \\
\geq 1 \text { severe } \\
\text { hypoglycaemia } \\
(\mathrm{n}=202)\end{array}$ & $\begin{array}{l}\text { Patients } \\
\text { without severe } \\
\text { hypoglycaemia } \\
(\mathrm{n}=414)\end{array}$ \\
\hline Females (\%) & 47.5 & 48.1 \\
\hline Age (years) & $26.3 \pm 6.7$ & $27.3 \pm 7.0$ \\
\hline Diabetes duration (years) & $10.0 \pm 7.5$ & $8.4 \pm 7.3^{\mathrm{a}}$ \\
\hline Age at onset of diabetes (years) & $16.3 \pm 8.7$ & $18.8 \pm 8.9^{\mathrm{b}}$ \\
\hline $\begin{array}{l}\text { Insulin dosage at 1-year } \\
\text { follow-up (IU/kg) }\end{array}$ & $0.69 \pm 0.23$ & $0.61 \pm 0.23^{b}$ \\
\hline $\begin{array}{l}\% \text { regular insulin of total daily } \\
\text { insulin dose at } 1 \text {-year follow-up }\end{array}$ & $44.4 \pm 14.6$ & $45.6 \pm 17.6$ \\
\hline $\begin{array}{l}\text { Mean } \mathrm{HbA}_{1 \mathrm{c}} \text { during follow-up } \\
(\%)\end{array}$ & $7.4 \pm 1.1$ & $7.7 \pm 1.4^{\mathrm{b}}$ \\
\hline $\begin{array}{l}\text { C-peptide }(\geq 0.1 \mathrm{nmol} / \mathrm{l}) \text { at } \\
\text { 1-year follow-up }(\%)\end{array}$ & 39.5 & $56.6^{\mathrm{b}}$ \\
\hline $\begin{array}{l}\text { Knowledge test ( } 39 \text { items) at } \\
1 \text {-year follow-up }\end{array}$ & $26.6 \pm 4.5$ & $26.6 \pm 4.9$ \\
\hline $\begin{array}{l}\text { Emotional coping (test score) } \\
\text { at } 1 \text {-year follow-up }{ }^{c}\end{array}$ & $15.3 \pm 3.9$ & $14.6 \pm 3.6^{\mathrm{a}}$ \\
\hline $\begin{array}{l}\text { Patients carrying emergency } \\
\text { carbohydrates at 1-year } \\
\text { follow-up }(\%)\end{array}$ & 74.3 & 80.9 \\
\hline $\begin{array}{l}\text { Severe hypoglycaemia during } \\
\text { the year preceding ITTP } \\
\text { (cases/patient/year) }^{\mathrm{d}}\end{array}$ & $0.51 \pm 1.3$ & $0.15 \pm 0.7^{\mathrm{b}}$ \\
\hline
\end{tabular}

Mean $\pm S D ;{ }^{a} p<0.05 ;{ }^{b} p<0.001 ;{ }^{c}$ high scores indicate low coping abilities; ${ }^{d}$ patients with diabetes duration $>1$ year at entry into the study $(n=538)$

The predictive value of $\mathrm{HbA}_{1 \mathrm{c}}$ levels for the occurrence of severe hypoglycaemia during follow-up was assessed by logistic regression analysis, adjusting for demographic, disease-related, psychosocial and behavioural variables (Table 2 ). In this model, which showed an appropriate goodness-of-fit (Hosmer- 


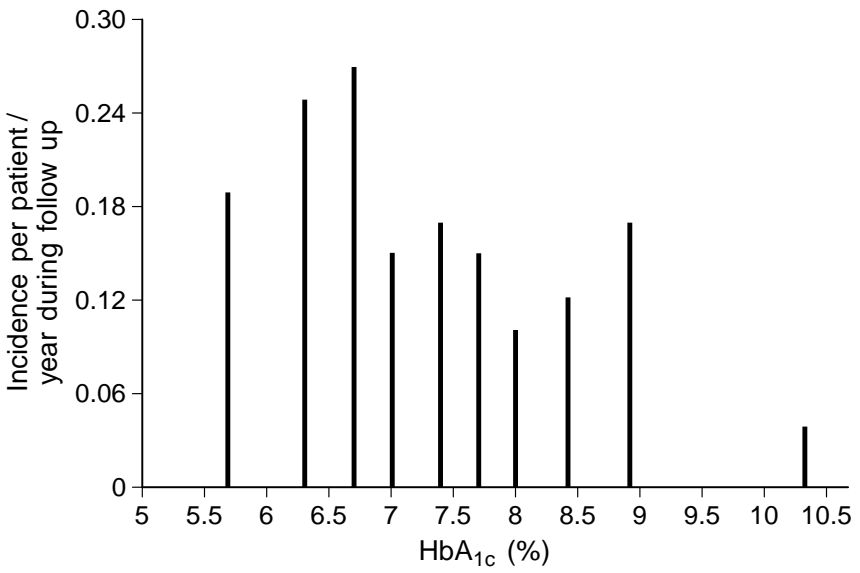

Fig. 2. $\mathrm{HbA}_{1 \mathrm{c}}$ (decile grouping) and severe hypoglycaemia during the 6-year follow-up period. ITTP, Intensified treatment and teaching programme

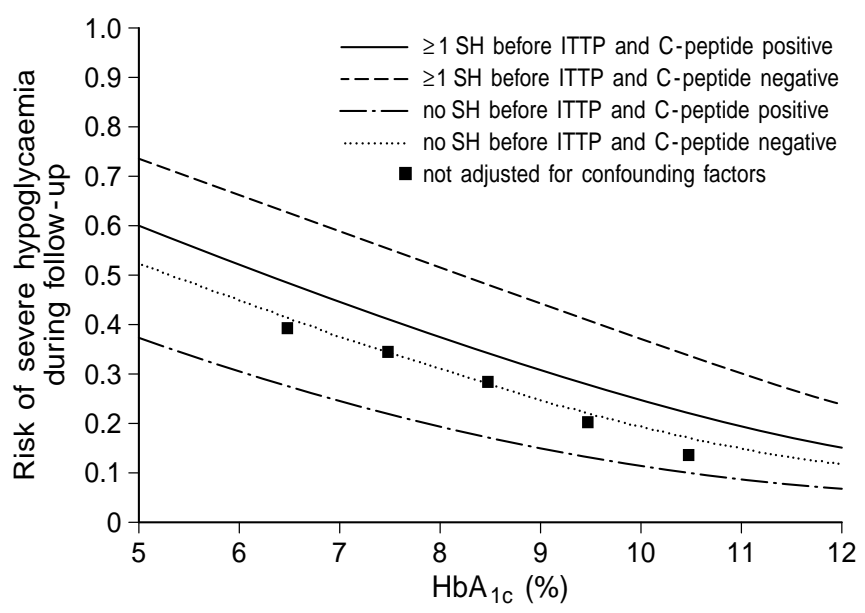

Fig. 3. Risk of severe hypoglycaemia within 6 years and $\mathrm{HbA}_{1 \mathrm{c}}$ adjusted for severe hypoglycaemia $(\mathrm{SH})$ during the year preceding the intensified treatment and teaching programme (ITTP), and C-peptide at the 1-year follow-up

Incidence of severe hypoglycaemia (per patient/ year) during the 6 -year follow-up

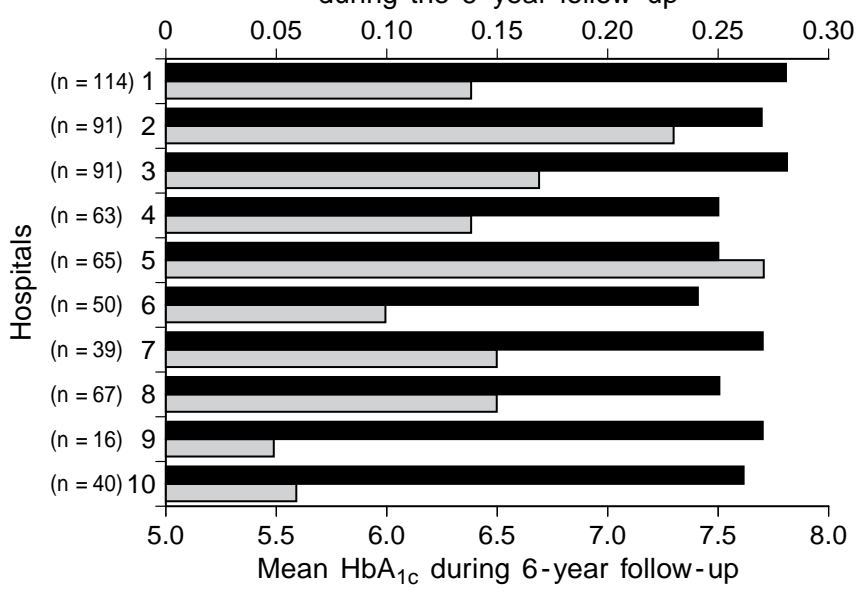

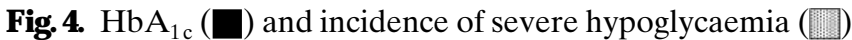
during the observation period between participating hospitals
Table 2. Logistic regression analysis (stepwise) of severe hypoglycaemia during the 6-year follow-up

\begin{tabular}{lll}
\hline Predictors & Chi-square & $\mathrm{p}$ value \\
\hline $\begin{array}{l}\text { Mean } \mathrm{HbA}_{1 \mathrm{c}} \text { during follow-up } \\
\begin{array}{l}\text { Severe hypoglycaemia during the year } \\
\text { preceding ITTP }\end{array}\end{array}$ & 19.25 & 0.0001 \\
$\begin{array}{l}\text { C-peptide }(\geq 0.1 \mathrm{nmol} / \mathrm{l}) \text { at 1-year } \\
\text { follow-up }\end{array}$ & 71.40 & 0.0007 \\
$\begin{array}{l}\text { Carrying emergency carbohydrates at } \\
\text { 1-year follow-up }\end{array}$ & 5.84 & 0.0052 \\
$\begin{array}{l}\text { Emotional coping at 1-year follow-up } \\
\text { Age at onset of diabetes }\end{array}$ & 5.74 & 0.0156 \\
\hline
\end{tabular}

Lemeshow-test; $p=0.12$ ), a lower mean $\mathrm{HbA}_{1 \mathrm{c}}$ during follow-up, a history of severe hypoglycaemia during the year preceding the ITTP, negative C-peptide levels, not carrying emergency carbohydrates, poorer scores on the coping scale, and a younger age at onset of diabetes were associated with a greater risk of severe hypoglycaemia during follow-up.

In order to visualize the relative importance and predictive value of the strongest explanatory variables, Figure 3 demonstrates the risk for subgroups of patients. C-peptide negative patients with at least one severe hypoglycaemia before the ITTP had the highest risk of severe hypoglycaemia, patients with no history of severe hypoglycaemia who were C-peptide positive had the lowest risk.

The centre in which the ITTP was performed (university diabetes centre vs general hospital) was not a significant predictor of the risk of severe hypoglycaemia. $\mathrm{HbA}_{1 \mathrm{c}}$ as well as the incidence of severe hypoglycaemia were comparable during the 6-year follow-up period between the specialized centre $(\mathrm{n}=114,7.8 \%, 0.14 \mathrm{cases} / \mathrm{patient} / \mathrm{year})$ and the nine general hospitals $(n=522,7.6 \%, 0.16$ cases/patient/ year).

The variation in the incidence of severe hypoglycaemia during follow-up between the 10 centres was between 0.05 and 0.27 cases/patient/year (Fig. 4). None of the centres had a higher incidence of severe hypoglycaemia during follow-up than the initial incidence of 0.28 for the whole sample.

\section{Discussion}

In this large cohort of intensively treated IDDM patients improvement of $\mathrm{HbA}_{1 \mathrm{c}}$ levels after participation in a structured ITTP was associated with a decrease in the risk of severe hypoglycaemia, and there was no linear or exponential relationship between $\mathrm{HbA}_{1 \mathrm{c}}$ and severe hypoglycaemia when simple group comparisons were carried out. In contrast to the DCCT, in the present study, treatment strategies as well as teaching methods were standardized and 
documented. Based on such a written curriculum, the ITTP as developed and evaluated at a specialized diabetes center, could be effectively and safely transferred to non-specialized hospitals.

In contrast, in the DCCT feasibility study, in the intensively treated group the percentage of patients experiencing hypoglycaemic coma increased from $10 \%$ in the year prior to enrollment to $20 \%$ during the first year of follow-up, while there was no change in the conventionally treated group (5 vs $6 \%$ ) [29]. Incidence data including all cases of severe hypoglycaemia are not reported for the year before enrollment into the DCCT. In the present study, $15 \%$ of patients had experienced at least one severe hypoglycaemia in the year preceding the ITTP and, although $\mathrm{HbA}_{1 \mathrm{c}}$ was improved, the percentage decreased to $10-12 \%$ for each year of the follow-up period.

In the DCCT, among intensively treated patients there was a strong inverse exponential relationship between $\mathrm{HbA}_{1 \mathrm{c}}$ levels and severe hypoglycaemia by using simple group comparison [1]. However, simple group comparison may lead to under- or overestimation of the association between $\mathrm{HbA}_{1 \mathrm{c}}$ and severe hypoglycaemia. In a previous publication of the DCCT it was reported that by applying complex regression analyses, $\mathrm{HbA}_{1 \mathrm{c}}$ levels and other patient-related potential predictors of severe hypoglycaemia could not constitute a convincing model with which to predict hypoglycaemia among intensively treated patients [16]. Although lower $\mathrm{HbA}_{1 \mathrm{c}}$ levels, a history of severe hypoglycaemia, a longer diabetes duration, lower stimulated C-peptide values, and higher insulin dosages were identified as predictors of severe hypoglycaemia more than $90 \%$ of the variance remained unexplained. The DCCT model used time intervals (duration between enrollment into the study and the first episode of severe hypoglycaemia) as the dependent variable to apply a proportional hazards life table regression analysis taking account of the varying duration of follow-up in each patient.

In the present study, after adjustment for confounding variables in the regression analysis, lower $\mathrm{HbA}_{1 \mathrm{c}}$ levels, a history of severe hypoglycaemia, negative C-peptide levels, poorer scores on the coping scale, lack of compliance to carry emergency carbohydrates and a younger age at onset of diabetes were associated with a greater risk of severe hypoglycaemia during follow-up. The population had identical follow-up periods and was divided into two subgroups: patients who experienced at least one severe hypoglycaemia during follow-up and patients who did not. For such a dichotomous dependent variable, a logistic regression model has to be applied and goodness of fit cannot be assessed in terms of explained variance. Therefore, the quality of the DCCT model and the model of the present study cannot be compared. However, predictors identified in both models are quite similar.
A lack of beta-cell responsiveness, accompanied by longer diabetes duration and higher insulin doses contribute to instability of glycaemic control [30-32]. This is in accordance with recent DCCT findings [33]. In these latter analyses, within the intensive treatment group, patients with sustained beta-cell responsiveness had a reduced risk of severe hypoglycaemia (risk reduction of $62 \%$ ) despite lower $\mathrm{HbA}_{1 \mathrm{c}}$ levels compared to $\mathrm{C}$-peptide negative patients. In addition, those patients randomized to the intensive therapy who had a diabetes duration of 5 years or less and sustained beta-cell function maintained a higher level of stimulated C-peptide over a longer period than patients on conventional treatment.

Although C-peptide was entered in the regression model, age at onset of diabetes was also a significant and independent predictor of the risk of severe hypoglycaemia. This is in accordance with previous analyses [19] indicating that patients diagnosed during adolescence had a poorer glycaemic control than other patients as adjustment to and treatment of diabetes appear particularly difficult during adolescence. It could be speculated that adolescents, especially when feeling psychologically vulnerable, tend to have a less favourable self-care behaviour, which might contribute to a higher risk of severe hypoglycaemia (e.g. excessive exercise without adjustment of insulin dosage, alcohol consumption, less frequent blood glucose self-monitoring) and maintain these detrimental strategies into adulthood [34].

Several studies have suggested that psychosocial factors play an important role for a successful selfmanagement of diabetes by the patient $[19,35,36]$. However, the majority of intervention studies regarding self-destructive behaviour focused on patients with high $\mathrm{HbA}_{1 \mathrm{c}}$ levels and severe hyperglycaemic symptoms [36]. The coping scale used in the present study comprised items reflecting feelings of personal responsibility for the management of diabetes ( Having diabetes means accepting responsibility for your own treatment) and the ability to cope with the demands of the disease (I feel quite capable of looking after my diabetes with minimum outside help). Two items were concerned with emotional support concerning diabetes and its treatment. The predictive value of the coping scale is in accordance with our previous analyses, indicating that active coping strategies, perceptions of self-efficacy and social support are closely associated with favourable glycaemic control taking account of both $\mathrm{HbA}_{1 \mathrm{c}}$ values and the frequency of severe hypoglycaemia [19,23].

Despite the similarity of predictors identified in the DCCT and in the present study, the validity of comparing different studies concerning intensified insulin therapy and the incidence of severe hypoglycaemia is weakened by differences in definitions of severe hypoglycaemia, methods of ascertainment, time intervals over which events were recorded or 
recalled, the populations studied, and methods of treatment. Such differences also compromise the comparability of the DCCT data and the results of the present study. Although comparable definitions of severe hypoglycaemia have been used in the DCCT feasibility study and the present study, in the DCCT the definition was subsequently extended to hypoglycaemia requiring assistance from another person. Only in the DCCT, patients with a history of repeated or unexplained severe hypoglycaemia have been excluded from intensified insulin therapy.

Theoretically, the strong exponential relationship between severe hypoglycaemia and $\mathrm{HbA}_{1 \mathrm{c}}$ in the DCCT trial could be due to hypoglycaemia requiring assistance by another person which was not examined in the present study. However, a detailed analysis of hypoglycaemic events in the DCCT revealed that the ratio of severe hypoglycaemia requiring assistance to hypoglycaemia with coma or seizures was comparable in the conventional and intensive treatment groups [37].

Another explanation for the different results in the DCCT and the present study might be that the structured ITTP in the 10 hospitals gave patients the opportunity to define individual treatment goals and to balance favourable $\mathrm{HbA}_{1 \mathrm{c}}$ levels and an acceptable risk of severe hypoglycaemia [23] whereas the DCCT primarily aimed at normalization of $\mathrm{HbA}_{1 \mathrm{c}}$ values. In the present study, analyses of subgroups of patients (quartile grouping according to $\mathrm{HbA}_{1 \mathrm{c}}$ at baseline) revealed that patients benefit differently from participation in the ITTP [23]. Patients with high $\mathrm{HbA}_{1 \mathrm{c}}$ levels at baseline $(10.8 \%)$ improved their glycaemic control substantially during follow-up $(8.3 \%)$ without increasing the incidence of severe hypoglycaemia $(0.21$ cases/patient/year before the programme, 0.15 during follow-up). Patients with good $\mathrm{HbA}_{1 \mathrm{c}}$ levels already before participation in the ITTP $(6.2 \%)$ raised their $\mathrm{HbA}_{1 \mathrm{c}}$ levels during follow-up $(6.9 \%)$ but decreased the incidence of severe hypoglycaemia by more than $50 \%$ ( 0.34 cases/patient/year before the programme, 0.15 during followup) [23].

The fear of severe hypoglycaemia should not deter patients and their health care providers from intensive treatment of IDDM, but the most appropriate range of $\mathrm{HbA}_{1 \mathrm{c}}$ should be discussed with each patient considering her/his individual risk factors. Under the circumstances of the present study, improvement of $\mathrm{HbA}_{1 \mathrm{c}}$, e.g. from 8 to $7 \%$ would not be associated with a substantial increase in the risk of severe hypoglycaemia (Fig. 3). In contrast, the absolute risk depends to a much greater extent on the C-peptide level and the history of severe hypoglycaemia.

Searching for risk factors of severe hypoglycaemia, it is obviously not sufficient to consider only patient characteristics as potential predictors. Nothing is known about the impact of physician-related factors as possible explanatory variables for the overall risk of severe hypoglycaemia associated with a particular insulin therapy at a particular diabetes centre. We do not know how attitudes or health beliefs of the treating physician or the health care team influence effectiveness and safety of insulin therapy and what kind of interactions there are between these attitudes and the quality and intensity of patient training, such as to recognize early, effectively treat, and, most importantly, prevent hypoglycaemia. Such factors might, in fact, be causally related to the documented centerto-center differences concerning the risk of severe hypoglycaemia in patients on intensified insulin therapy. It would be an interesting challenge in the near future to develop a comprehensive model including a variety of potential predictors aiming to identify an increasing proportion of the variance in hypoglycaemic episodes. Apart from health care team related factors and analyses of the quality of treatment and teaching programmes, such an evaluation would have to include a systematic assessment of the patients' hypoglycaemic awareness.

A cknowledgements. We acknowledge the support by the P. Klöckner Stiftung, Duisburg, Germany (grants to Prof. M. Berger), and we thank Dr. rer. biol. hum. Ralf Bender, statistitian, for the analyses of the data.

\section{References}

1. The Diabetes Control and Complications Trial Research Group (1993) The effect of intensive treatment of diabetes on the development and progression of long-term complications in insulin-dependent diabetes-mellitus. N Engl J Med 329: 977-986

2. Egger M, Davey Smith G, Diem P (1996) Risk of adverse effects of intensified treatment IDDM: a meta-analysis. Diabetologia 39 [Suppl]:A52 (Abstract)

3. The Diabetes Control and Complications Trial Research Group (1995) Implementation of treatment protocols in the DCCT. Diabetes Care 18: 361-376

4. Pless IB, Heller A, Belmonte M, Zvagulis I (1988) Expected diabetic control in childhood and psychosocial functioning in early adult life. Diabetes Care 11: 387-392

5. Aman J, Karlsson I, Wranne L (1989) Symptomatic hypoglycaemia in childhood diabetes: a population-based questionnaire study. Diabet Med 6: 257-261

6. MacLeod KM, Hepburn DA, Frier BM (1993) Frequency and morbidity of severe hypoglycaemia in insulin-treated diabetic patients. Diabet Med 10: 238-245

7. Pieber TR, Brunner GA, Schnedel WJ, Schattenberg S, Kaufmann P, Krejs GJ (1995) Evaluation of a structured outpatient group education program for intensive insulin therapy. Diabetes Care 18: 625-630

8. Pampanelli S, Fanelli C, Lalli C et al. (1996) Long-term intensive insulin therapy in IDDM: effects on $\mathrm{HbA}_{1 \mathrm{c}}$, risk for severe and mild hypoglycaemia, status of counterregulation and awareness of hypoglycaemia. Diabetologia 39: 677-686

9. Mecklenburg RS, Benson EA, Benson JW et al. (1994) Acute complications associated with insulin infusion pump therapy. JAMA 252: 3265-3269 
10. Jörgens V, Grüsser M, Bott U, Mühlhauser I, Berger M (1993) Effective and safe translation of intensified insulin therapy to general internal medicine departments. Diabetologia 36: 99-105

11. Bending JJ, Pickup JC, Keen H (1985) Frequency of diabetic ketoacidosis and hypoglycemic coma during treatment with continuous subcutaneous insulin infusion. Am J Med 79: 685-691

12. Chantelau E, Spraul M, Mühlhauser I, Gause R, Berger M (1989) Long-term safety, efficacy and side-effects of continuous subcutaneous insulin infusion treatment for type 1 (insulin-dependent) diabetes mellitus: a one centre experience. Diabetologia 32: 421-426

13. Mühlhauser I, Bruckner I, Berger M et al. (1987) Evaluation of an intensified treatment and teaching programme as routine management of type 1 (insulin-dependent) diabetes. The Bucharest-Düsseldorf Study. Diabetologia 30: 681-690

14. Starostina EG, Antsiferov M, Galstyan GR et al. (1994) Effectiveness and cost-benefit analysis of intensive treatment and teaching programmes for type 1 (insulin dependent) diabetes mellitus in Moscow-blood glucose versus urine glucose self-monitoring. Diabetologia 37: 170-176

15. Berger M, Mühlhauser I (1995) Implementation of intensified insulin therapy: a European perspective. Diabet Med 12: 201-208

16. The Diabetes Control and Complications Trial Research Group (1991) Epidemiology of severe hypoglycaemia in the Diabetes Control and Complications Trial. Am J Med 90: 450-459

17. Wang PH, Lau J, Chalmers TC (1993) Meta-analysis of effects of intensive blood-glucose control on late complications of type 1 diabetes. Lancet 341: 1306-1309

18. Mühlhauser I, Bott U, Overmann H et al. (1995) Liberalized diet in patients with type 1 diabetes. J Int Med 237: 591-597

19. Bott U, Jörgens V, Grüsser M, Bender R, Mühlhauser I, Berger M (1994) Predictors of glycaemic control in type 1 diabetic patients after participation in an intensified treatment and teaching programme. Diabet Med 11: 362-371

20. Mühlhauser I, Bender R, Bott U et al. (1996) Cigarette smoking and the progression of retinopathy and nephropathy in type 1 diabetes. Diabet Med 13: 536-543

21. Scholz V, Grüßer M, Bott U, Jörgens V (1990) Unterrichtskarten zur Schulung von Typ-I-Diabetikern. Kirchheim Verlag, Mainz

22. Bott U, Scholz V, Grüßer M, Jung V, Jörgens V, Berger M (1988) Evaluation of a knowledge test with 546 type 1 (insulin-dependent) diabetic patients in 10 centres. Diabetologia 31 [Suppl]:473A (Abstract)
23. Bott U (1996) Psychosoziale Aspekte der Krankheitsbewältigung und ihre Beziehung zum Therapieerfolg: Evaluation krankheitsspezifischer Fragebogen bei Typ-IDiabetikern. Peter Lang Verlag, Frankfurt

24. Dunn SM, Smartt HH, Beeney LJ, Turtle JR (1986) Measurement of emotional adjustment in diabetic patients: Validity and reliability of ATT39. Diabetes Care 9: 480-489

25. Bott U (1995) Emotionale Einstellungen bei Typ-I-Diabetikern: Streß und Streßbewältigung. In: Kohlmann CW, Kulzer B (eds.) Diabetes und Psychologie - Diagnostische Ansätze. Hans Huber, Bern Göttingen Toronto Seattle, pp 83-96

26. Brosius G (1988) SPSS/PC + Basics and graphics. Mc Graw-Hill, Hamburg New York

27. Brosius G (1989) SPSS/PC + Advanced statistics and tables. Mc Graw-Hill, Hamburg New York

28. SAS Technical Report P-200, SAS/STAT Software (1990) CALIS and LOGISTIC Procedures, Release 6.04. SAS Institute Inc., Cary, NC

29. The Diabetes Control and Complications Trial Research Group (1987) Diabetes control and complications trial (DCCT): Results of feasibility study. Diabetes Care 10: 119

30. Fukuda M, Tanaka A, Tahara Y et al. (1988) Correlation between minimal secretory capacity of pancreatic b-cells and stability of diabetic control. Diabetes 37: 81-88

31. The DCCT Research Group (1987) Effects of age, duration and treatment of insulin dependent diabetes mellitus on residual b-cell function: observations during eligibility testing for the Diabetes Control and Complications Trial (DCCT). J Clin Endocrinol Metab 65: 30-37

32. Reynolds C, Molnar GD, Horwitz DL, Rubenstein AH, Taylor WF, Jiang NS (1977) Abnomalities of endogenous glucagon and insulin in unstable diabetes. Diabetes 26: 36

33. Steffes M, Tamborlane W, Becker D, Palmer J, Cleary P (1996) The effect of intensive treatment on residual b-cell function in the Diabetes Control and Complications Trial. Diabetes 45: 18A

34. Wysocki T, Hough BS, Ward KM, Green LB (1992) Diabetes mellitus in the transition to adulthood: adjustment, selfcare, and health status. J Dev Behav Pediatr 13: 194-201

35. Cox DJ, Gonder-Frederick L (1992) Major developments in behavioral diabetes research. J Consult Clin Psychol 60: 628-638

36. Rubin RR, Peyrot M (1992) Psychosocial problems and interventions in diabetes: a review of the literature. Diabetes Care 15: 1640-1657

37. The Diabetes Control and Complications Trial Research Group (1995) Adverse events and their association with treatment regimens in the Diabetes Control and Complications Trial. Diabetes Care 18: 1415-1427 